\title{
Evaluation of arsenic contamination potential using indicator kriging in the Yun-Lin aquifer (Taiwan)
}

\author{
Chen-Wuing Liu*, Cheng-Shin Jang, Chung-Min Liao \\ Department of Bioenvironmental Systems Engineering, National Taiwan University, Taipei 106, Taiwan, ROC
}

Received 31 May 2003; accepted 3 September 2003

\begin{abstract}
Data on the quality of groundwater obtained from several multi-level monitoring wells indicated that arsenic (As) concentration far exceeds the drinking water supply standard in the coastal aquifer of the Yun-Lin, Taiwan. In this study, an estimated As probability risk was computed using indicator kriging to assess the As contamination potential of exceeding the drinking water supply standard in the Yun-Lin county. A three-dimensional (3D) spatial variability model was presented to analyze anisotropically the variation of As concentration using a multi-level threshold indicator variable. This 3D estimator overcomes the scarcity of the data and establishes a vertical correlation of measured As data. The results indicate high As pollution probability in the coastal area and in the Pei-Kang river basin. The highest probability, 0.92, of the As pollution is in the shallow aquifer of the Kou-Hu. The contamination potential of As is primarily within an aquifer depth of $180 \mathrm{~m}$. The contaminated aquifer $(<180 \mathrm{~m})$ is not suitable for supplying drinking water. The contamination potential of As is low at the depths of more than $190 \mathrm{~m}$. However, the probabilities associated with the As pollution still exceed 0.2 in the deep aquifer of four coastal townships of the Yun-Lin, and may pose risks to human health if the groundwater is used for drinking.
\end{abstract}

(c) 2003 Elsevier B.V. All rights reserved.

Keywords: Arsenic; Contamination potential; Drinking water standard; Complex aquifer; Indicator kriging

\section{Introduction}

Arsenic (As) has been well documented as a major risk factor for blackfoot disease (Shen and Chin, 1964). Blackfoot disease was once common on the southwestern coast of Taiwan (Chiou, 1996). The residents had used high-arsenic artesian well water over 50 years (Tseng, 1977). Largescale studies on the association between arsenic

\footnotetext{
*Corresponding author. Tel.: +886-2-2362-6480; fax: + 886-2-2363-9557.

E-mail address: lcw@gwater.agec.ntu.edu.tw (C.-W. Liu).
}

complexes in well water and age-adjusted mortality from diabetes (Lai et al., 1994), hypertension (Chen et al., 1995) and cancers of the nasal cavity, lung, liver, bladder, kidney and prostate (Wu et al., 1989; Chen and Wang, 1990) yield mutually supporting findings. Patients with blackfoot disease had a substantially raised incidence of cancer, after adjustment for cumulative arsenic exposure.

Yen et al. (1980) presented a geological environment model to describe the origin of high arsenic concentrations in the shallow sedimentary basin of southwestern Taiwan. Changes in sea 
level significantly influence the composition and structure of the geological environment. The sedimentary basin is formed by the alternating invasion and retreat of sea water with interlayered formations of marine and non-marine sequences. The marine sequences with fine sediment, ranging from clay, through silt to fine sand have a relatively high arsenic content, which is accumulated and deposited in the formation. Other sources of arsenic contamination are associated with the excess use of a wide range of pesticides, herbicides and agro-fertilizers ( $\mathrm{Li}$ et al., 1979). The current drinking water supply standard of As in Taiwan is 50 $\mu \mathrm{g} / \mathrm{l}$-much lower than the background As concentration level $(200-2500 \mu \mathrm{g} / \mathrm{l})$ in the Yun-Lin area. Groundwater has been abundantly used as an alternative to surface water, especially in the southwestern coastal region, such as in the Yun-Lin, where surface water resources are severely deficient, due to the high demand for domestic, irrigation, aquacultural and industrial utilization. As may be directly taken up by drinking water, damaging human health; it may also indirectly enter the food-chain through various paths and poses a risk to human health. In 2001, the soil and groundwater remediation act enforced $25 \mu \mathrm{g} / 1$ and 250 $\mu \mathrm{g} / \mathrm{l}$ stringent standards for groundwater within and outside protected areas from which drinking water is supplied, respectively.

The spatial distribution of contaminated groundwater commonly exhibits some heterogeneity. However, only a small proportion of in-situ data can be analyzed in a field investigation, due to time and cost constraints. Consequently, sparse measured data contain considerable uncertainty. Geostatistics are widely used to estimate the spatial variability and distribution of field data with uncertainty. Indicator kriging is the most commonly used non-parametric geostatistical method. Indicator kriging makes no assumptions on the underlying invariant distribution, and $0 \sim 1$ indicator transformation of data make the predictor robust to outliers (Cressie, 1993). At an unsampled location, the values estimated by indicator kriging represent a probability that is less than a specified threshold. That is, the expected value at the location derived from indicator data is equivalent to the cumulative distribution function of the variable
(Smith et al., 1993). Indicator kriging has been frequently applied to the pollution of soil by heavy metals. For example, Smith et al. (1993) and Oyedele et al. (1996) used multivariate indicator kriging to analyze the quality of soil; Lin et al. (2002) applied indicator kriging to delineate the variation and pollution sources of heavy metals in agricultural land; Juang and Lee (1998), Castrignanò et al. (2000) and van Meirvenne and Goovaerts (2001) adopted multi-level-threshold indicator kriging to estimate the probability distribution of heavy metal pollution in the field. Geostatistical indicator methods have also been applied in the lithological classification of rocks (McCord et al., 1997; Fogg et al., 1999) and in the estimation of contamination probability in groundwater aquifers (Istok and Pautman, 1996).

Methods for assessing the vulnerability of aquifers are typically divided into three groups: (1) overlay and index methods, (2) methods that involve process-based simulation models, and (3) statistical methods (NRC, 1993). Vulnerability assessments generally include uncertainty. The probabilitic outcomes indicate the unreliability of the assessment. Furthermore, the occurrence probabilities of contamination can be used to reveal the relative contamination potential under uncertainty conditions of sparse measured data.

This work applies indicator kriging to assess the contamination potential of As in the Yun-Lin. The As formation and source in the Yun-Lin aquifers are highly associated with sedimentary environments. The study assumed that the As distributions of three aquifers were vertically correlated owing to similar formation environments. A three-dimensional (3D) spatial variability and distribution of As probabilistic risk and its associated contamination potential are constructed and assessed using multi-level-threshold indicator kriging. The determined As contamination probability is overlaid on a township map of the Yun-Lin county, using a geographic information system (GIS), to delineate the varying contamination potential and the contamination sources of As. The established spatial probability risk distribution is a useful guide that helps the water service company to place wells to meet the water quality standards of various water supply needs. 


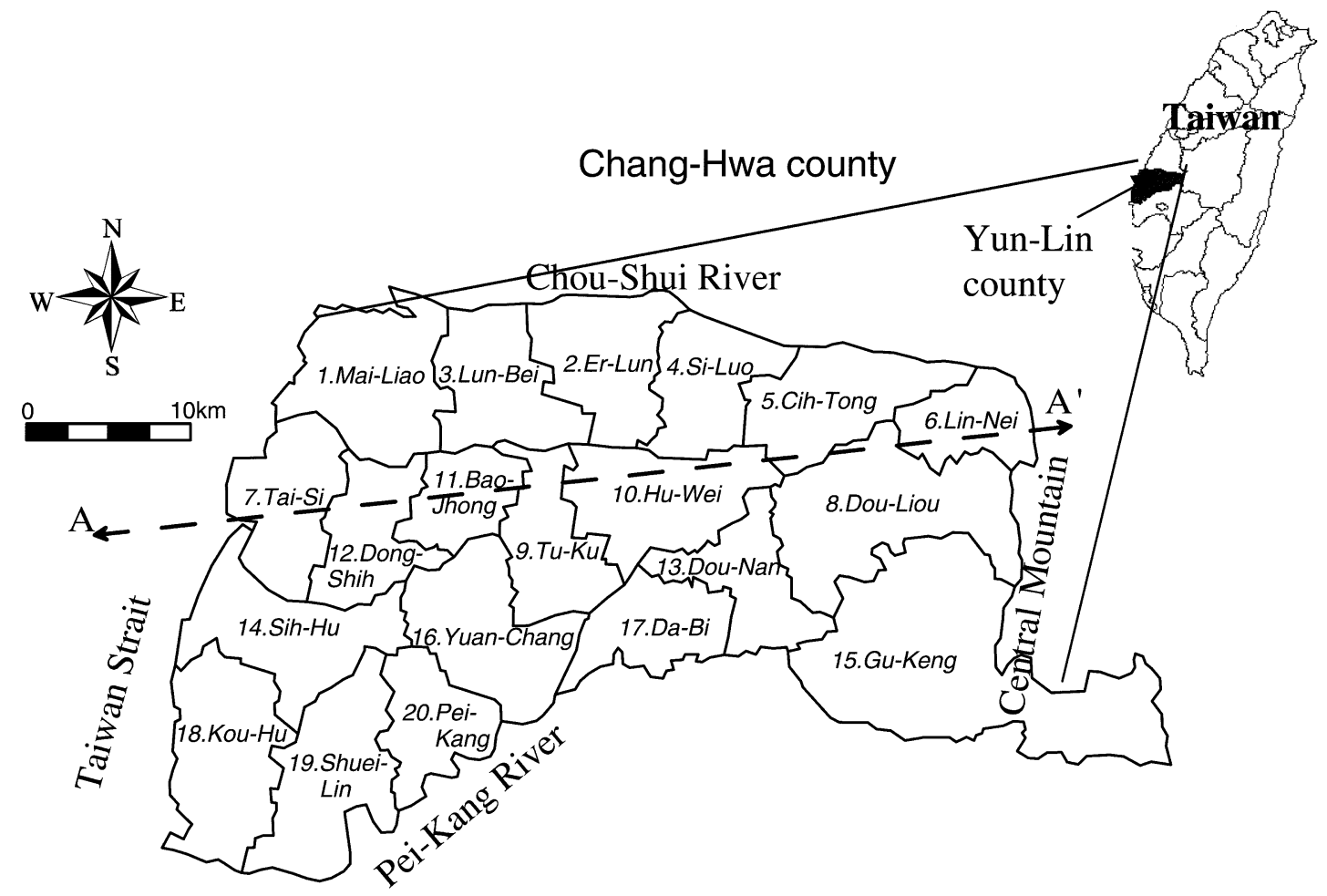

Fig. 1. Locations of twenty townships in the Yun-Lin county, Taiwan.

\section{Study area}

The Yun-Lin County is located in the southern part of the Chou-Shui River alluvial fan (Fig. 1). The area is enclosed by the Taiwan Strait to the west, the Central Mountain to the east, the ChouShui river to the north and the Pei-Kang river to the south. Chou-Shui and Pei-Kang are the two major rivers that flow through the area. The area is approximately $1000 \mathrm{~km}^{2}$, and extends $48 \mathrm{~km}$ from east to west and $24 \mathrm{~km}$ from north to south. The average annual precipitation is $1417 \mathrm{~mm}$. Rainfall is concentrated in the five-month period from May to September.

Agriculture is the primary source of revenue in the Yun-Lin. The industrial sector has grown rapidly, causing the average income of farmers to fall considerably below that of workers in other sectors. Therefore, many farmers have converted their croplands into fishponds to boost earnings. A large amount of groundwater has been extracted from the aquifer to supply these fishponds. The extraction has caused severe land subsidence, seawater intrusion, flooding and deterioration of the surrounding environment (Tsao and Wang, 1984; Shen, 1989; Geng et al., 1994).

Between 1992 and 1998, the government implemented a 7-year comprehensive groundwater monitoring network plan to investigate the hydrogeological characteristics of the main groundwater system in Taiwan. The new groundwater-monitoring network in the Chou-Shui River alluvial fan was quickly implemented. It includes 77 hydrogeological investigation stations and 188 groundwater-monitoring wells in different aquifers (Taiwan Sugar Company, 1997). A hydrogeological study revealed that the alluvial fan was of the late Quaternary age and was partitioned primarily into proximal-fan, mid-fan and distal-fan areas. In the subsurface hydrogeological analysis to a depth of approximately $300 \mathrm{~m}$, the formation can be divided into six interlayered sequences, including 


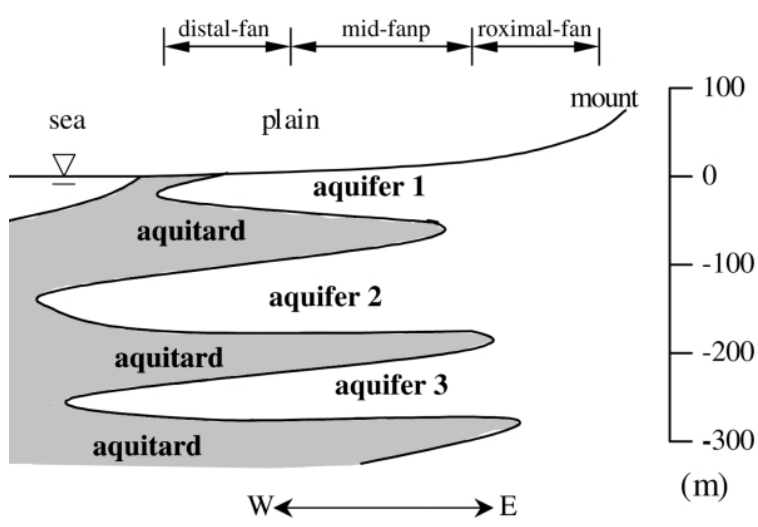

Fig. 2. Conceptual hydrogeological profile in the Yun-Lin county, Taiwan along transect $\mathrm{A}-\mathrm{A}^{\prime}$ in Fig. 1.

three marine sequences and three non-marine sequences, in the distal-fan and the mid-fan areas. Generally, the non-marine sequences, with coarse sediment, ranging from medium sand to gravel of high permeability, can be considered as aquifers, whereas the marine sequences with fine sediment, can be considered as aquitards (Fig. 2). The hydrogeological formation of the proximal-fan, which consists entirely of gravel and sand, is regarded as an unconfined aquifer and an important groundwater recharge area (Central Geological Survey, 1999).

The south side of the Chou-Shui River alluvial fan has 107 monitoring wells, including 23 wells in aquifer 1 with depths of less than $50 \mathrm{~m}, 54$ wells in aquifer 2 with depths between 60 and 180 $\mathrm{m}$, and 24 wells in aquifer 3 with depths between 190 and $280 \mathrm{~m}$. Additionally, six wells have depths of more than $280 \mathrm{~m}$.

The Taiwanese Water Supply Company had a total of 235 groundwater right permits in the YunLin, issued by the Water Resources Agency in 2002. The averaged water quantity permit was $0.03 \mathrm{~m}^{3} / \mathrm{s}$ for domestic use, clearly indicating that groundwater remains a major resource for drinking in the Yun-Lin.

From 1999 to 2001, the Taiwan Sugar Company (2001) undertook three groundwater quality surveys in the Chou-Shui River alluvial fan; the most recent survey in 2001 focused only on the wells in which the concentration of As was high. The survey analyzed 31 water quality items including the concentration of As. The measured As concentrations in the Yun-Lin are typically higher than those in the Chang-Hwa. This investigation thus focuses on assessing the As contamination potential in the Yun-Lin. Table 1 presents the descriptive statistical results of data from three groundwater quality surveys. The As concentrations exhibit a positively skewed distribution with mostly low As concentrations. Approximately $40 \%$ of the As concentrations were below the detection limit $(<10$ $\mu \mathrm{g} / \mathrm{l})$ in the first two surveys, and the maximum As concentration increased steadily with time. High As concentrations were found in the west and southwest shallow monitoring wells (Fig. 3).

Fig. 4 plots the vertical distribution of measured As concentrations. The highest As concentration is at a depth of $40 \mathrm{~m}$ below sea-level. Notably, the As concentration of a few samples taken at a depth of more than 300-m depth exceeded the drinking water limit, suggesting that the use of deep groundwater still poses a risk to human health. The correlation coefficient of measured As concentrations in 1999-2000, and in 2000-2001 are 0.85 and 0.93 , respectively, suggesting that the variation of As concentration is mild. The As concentrations in 2000 were slightly higher than those in 1999;

Table 1

Statistics of measured As concentrations in groundwater from 1999 to 2001 in the Yun-Lin county, Taiwan

\begin{tabular}{llll}
\hline Statistics & \multicolumn{2}{l}{ Year } \\
\cline { 2 - 4 } & 1999 & 2000 & 2001 \\
\hline Well number & 107 & 107 & 35 \\
Average $(\mu \mathrm{g} / 1)$ & 53.9 & 65.9 & 168 \\
Standard deviation $(\mu \mathrm{g} / 1)$ & 91 & 120 & 200 \\
Skewness & 2.99 & 3.00 & 2.34 \\
Minimum $(\mu \mathrm{g} / 1)$ & $<10$ & $<10$ & 20 \\
Maximum $(\mu \mathrm{g} / 1)$ & 570 & 640 & 830 \\
Percentile $(\mu \mathrm{g} / 1)$ & & & \\
10 & $<10$ & $<10$ & 45 \\
20 & $<10$ & $<10$ & 50 \\
30 & $<10$ & $<10$ & 58 \\
40 & 10 & $<10$ & 75 \\
50 & 17 & 16 & 87 \\
60 & 27 & 25 & 116 \\
70 & 40 & 46 & 152 \\
80 & 78 & 94 & 190 \\
90 & 143 & 163 & 590 \\
\hline
\end{tabular}



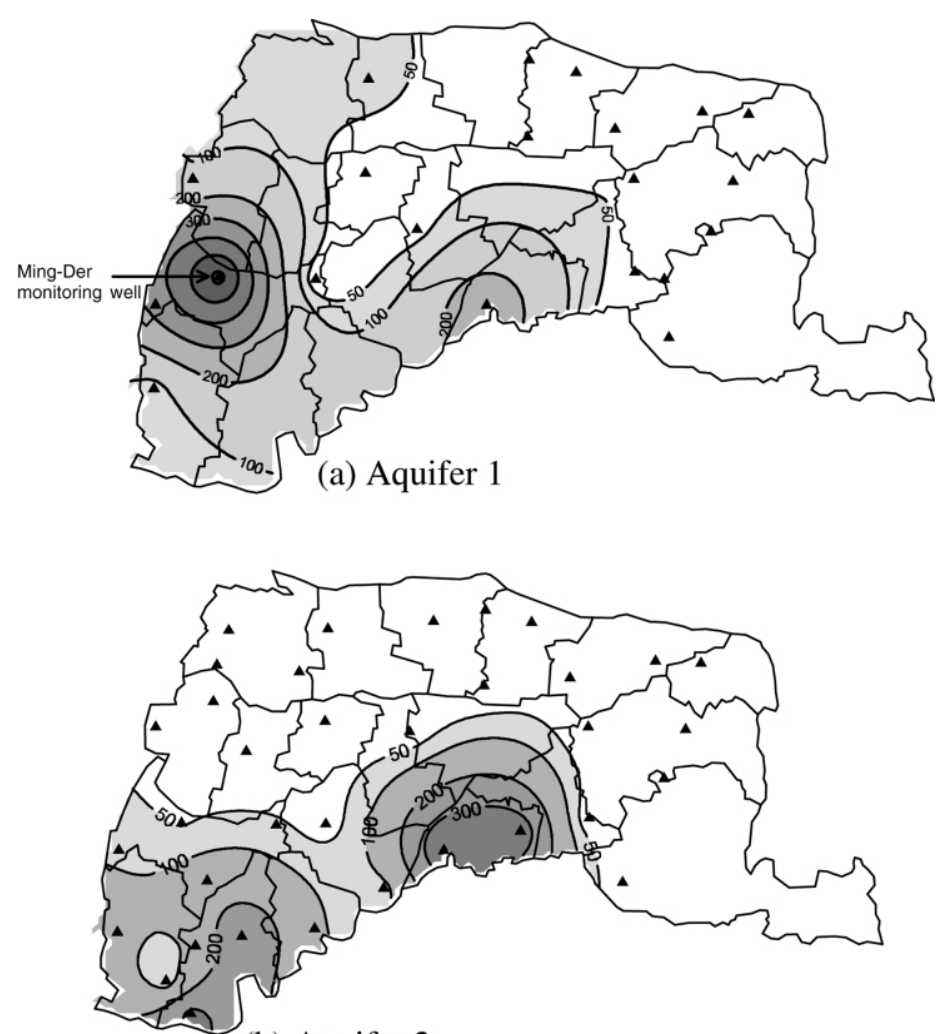

(b) Aquifer 2

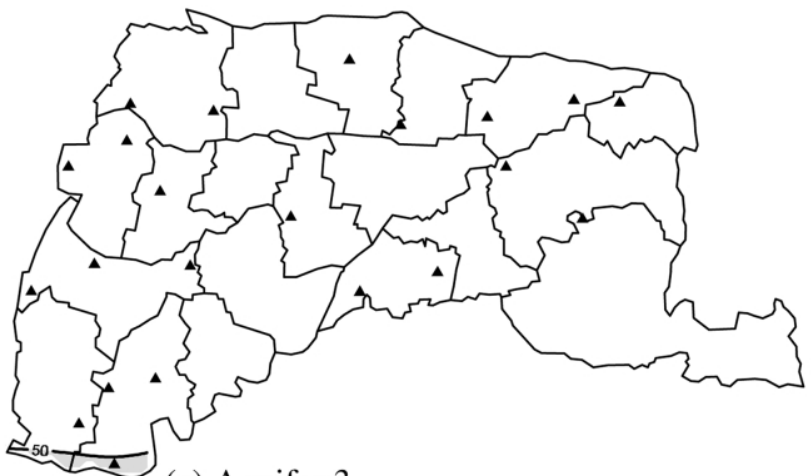

(c) Aquifer 3

$\boldsymbol{\Delta}$ location of monitoring well

Fig. 3. As concentration contours of three aquifers in the Yun-Lin county, Taiwan (drawn by kriging method of Surfer ${ }^{\circledR}, \mu g / 1$ ). 


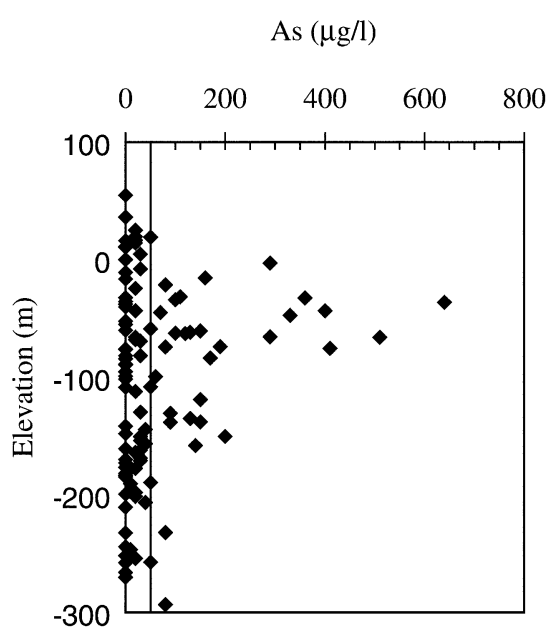

Fig. 4. Vertical distribution of measured As concentrations in 2000 .

therefore, the As concentrations measured in 2000 are adopted herein to assess the contamination potential in the Yun-Lin.

\section{Method}

\subsection{Variogram analysis}

Geostatistical methods are based on the regionalized variable theory that states that variables in an area exhibit both random and spatially structured properties (Journel and Huijbregts, 1978). The geostatistical spatial assumption is generally made that the regionalized variable is second-order stationary. A geostatistical variogram of the data should first be determined. The variogram quantifies the spatial variability of random variables between two sites. In practice, an experimental variogram, $\hat{\gamma}(h)$, is computed as,

$\hat{\gamma}(h)=\frac{1}{2 N(h)}\left\{\sum_{i=1}^{N(h)}\left[z\left(u_{i}+h\right)-z\left(u_{i}\right)\right]^{2}\right\}$

where $\hat{\gamma}(h)$ denotes the variogram for an interval lag distance class $h ; N(h)$ represents the number of pairs for an interval lag distance class $h$, and $z\left(u_{i}\right)$ and $z\left(u_{i}+h\right)$ are the values of the regionali- zed variables of interest at locations $u_{i}$ and $u_{i}+h$, respectively.

The experimental variogram, $\hat{\gamma}(h)$, is fitted a theoretical model, $\gamma(h)$, such as spherical, exponential, or Gaussian, to determine three parameters, including the nugget effect $\left(c_{o}\right)$, the sill $(c)$ and the range $(a)$. These models are defined as follows (Isaaks and Srivastava, 1989).

Spherical model:

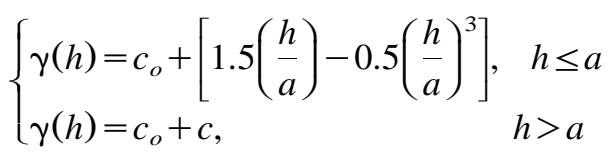

Exponential model:

$\gamma(h)=c_{o}+c\left[1-\exp \left(-3 \frac{h}{a}\right)\right]$

Gaussian model:

$\gamma(h)=c_{o}+c\left[1-\exp \left[-\left(\frac{3 h}{a}\right)^{2}\right]\right]$.

Variogram can be computed in different directions to detect any anisotropy of the spatial variability. An anisotropic model generally includes geometric anisotropy and zonal anisotropy. The former type of anisotropy yields variograms having the same structural shape and maximum variability (sill) but a direction-dependent range for the spatial correlation. The latter type, however, is defined by sills varying with direction (Goovaerts, 1997).

The study area is a multi-layered aquifer system. The spatial scale in the horizontal direction is very different from that in the vertical direction: the distance between pairs of groundwater monitoring wells in the horizontal direction exceeds $3 \mathrm{~km}$, whereas the largest difference between two measurements of As concentration in the vertical direction is less than $0.35 \mathrm{~km}$. This work thus uses a 3D spatial pairing strategy for calculating an experimental variogram in the same aquifer (Type I), in different aquifers (Type II) and in different wells at the same investigation station in the vertical direction (Type III) (Fig. 5). The first two types 


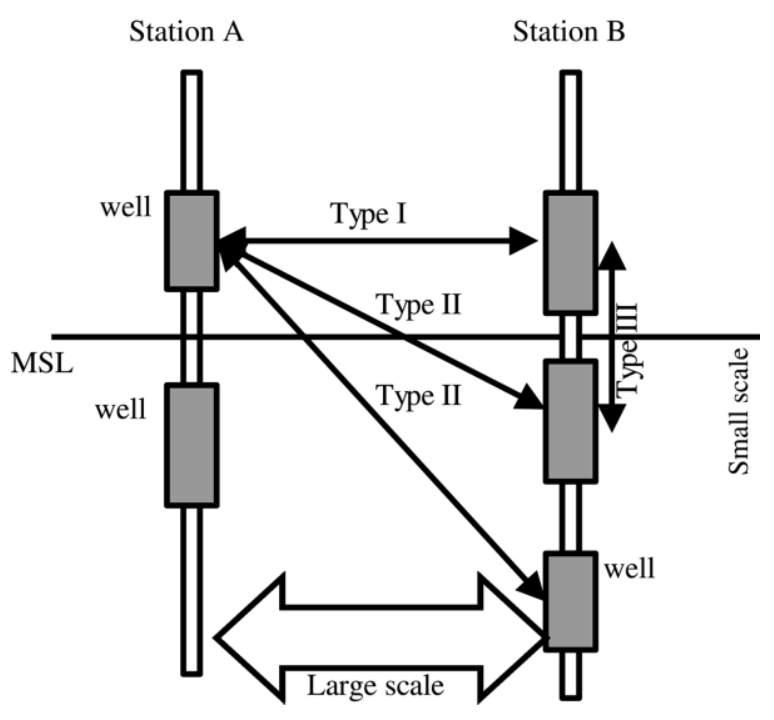

Fig. 5. Three searching pair types for calculating experimental variograms (enlarging in the vertical direction). MSL is the mean sea level.

(Types I and II), whose maximum angles between pair vectors and the horizontal direction are under $7^{\circ}$, are defined as approximately horizontal and as large-scale searching pairs.

The third type (Type III) is defined as a vertical and small-scale search pair. The 3D spatial variability has been frequently used in estimating the hydraulic conductivity distribution (Hess et al., 1992; Rehfeldt et al., 1992; Boman et al., 1995; Eggleston et al., 1996; Nakaya et al., 2002; Liu et al., 2002). The 3D analysis differentiates the horizontal direction (large-scale) from the vertical direction (small-scale) zonal anisotropy using a nested variogram. Geometric anisotropy is performed to evaluate the horizontal anisotropic variability. The full 3D anisotropy analysis searches for pairs in a spiral along three principal axes, overcoming the sparse measured data in each aquifer, increasing the vertical correlation among measured data, and yielding a small estimation error (Liu et al., 2002).

\subsection{Indicator kriging}

Indicator kriging is a non-parametric geostatistical method for estimating the probability of exceeding a specific threshold value, $z_{k}$, at a given location. In indicator kriging, the stochastic variable, $Z(u)$, is transformed into an indicator variable with a binary distribution, as follows:

$I\left(u ; z_{k}\right)=\left\{\begin{array}{ll}1, & \text { if } Z(u) \leq z_{k}, \quad k=1,2, \ldots, m \\ 0, & \text { otherwise }\end{array}\right.$.

The expected value of $I\left(u ; z_{k}\right)$, conditional to $n$ surrounding data, can be expressed as,

$$
\begin{aligned}
& E\left[I\left(u ; z_{k} \mid(n)\right)\right]=\operatorname{Prob}\left\{Z(u) \leq z_{k} \mid(n)\right\} \\
& =F\left(u ; z_{k} \mid(n)\right) \\
& P\left(u ; z_{k} \mid(n)\right)=1-F\left(u ; z_{k} \mid(n)\right)
\end{aligned}
$$

where $F\left(u ; z_{k} \mid(n)\right)$ is the conditional cumulative distribution function of $Z(u) \leq z_{k}$, and $P\left(u ; z_{k} \mid(n)\right)$ is the probability that $Z(u)>z_{k}$. At an unsampled location, $u_{0}$, an estimation must utilize indicator kriging and the indicator estimator, $I^{*}\left(u_{0} ; z_{k}\right)$, according to,

$I^{*}\left(u_{0} ; z_{k}\right)=\sum_{j=1}^{n} \lambda_{j}\left(z_{k}\right) I\left(u_{j} ; z_{k}\right)$

where $I\left(u_{j} ; z_{k}\right)$ represents the values of the indicator at measured locations, $u_{j}, j=1,2, \ldots, n$, and $\lambda_{j}$ is the weighting factor of $I\left(u_{j} ; z_{k}\right)$ in estimating $I *\left(u_{0} ; z_{k}\right)$. Indicator kriging estimation must be unbiased and with minimum estimation error variance; that is,

$E\left[I^{*}\left(u_{0} ; z_{k}\right)-I\left(u_{0} ; z_{k}\right)\right]=0$

$\operatorname{Var}\left[I^{*}\left(u_{0} ; z_{k}\right)-I\left(u_{0} ; z_{k}\right)\right]$ is minimum.

The weights, $\lambda_{j}$, are solution of the following system,

$$
\begin{cases}\sum_{j=1}^{n} \lambda_{j}\left(z_{k}\right) \gamma_{I}\left(u_{i}-u_{j} ; z_{k}\right)-\mu\left(z_{k}\right)= & \gamma_{I}\left(u_{i}-u_{0} ; z_{k}\right) \\ \sum_{j=1}^{n} \lambda_{j}\left(z_{k}\right)=1 & , \text { to } n\end{cases}
$$

where $\mu\left(z_{k}\right)$ is the Lagrange multiplier, $\gamma_{I}\left(u_{i}-\right.$ $u_{j} ; z_{k}$ ) specifies the variogram value between the 
indicator variables at the $i$ th and $j$ th sampling points; $\gamma_{I}\left(u_{i}-u_{0} ; z_{k}\right)$ is the variogram value between the indicator variables at the $i$ th sampling point $u_{0}$.

As concentration is the spatial attribute of interest. The sampling frequency distribution of the contaminant generally exhibits a severe, positive bias, which makes non-parametric estimation method more appropriate. The use of a single threshold cannot accurately describe the probability distribution. Goovaerts (1997) suggested the use of $5 \sim 15$ thresholds in indicator kriging to estimate the spatial variable. However, the probability estimate at each threshold may exceed unity or be smaller than zero, and order-relation deviation may occur, violating the monotonic increase in the conditional cumulative distribution function. This investigation sets up six thresholds to determine the conditional cumulative distribution function at each grid point.

\subsection{Cross-validation}

In a cross-validation procedure, measured data are dropped one at a time and re-estimated from some of the remaining neighboring data. Each datum is replaced in the data set once it has been re-estimated. The two parameters are computed as follows (Isaaks and Srivastava, 1989; Deutsch and Journel, 1998).

$$
\begin{aligned}
& \mathrm{KME}=\frac{1}{N} \sum_{i=1}^{N}\left[I^{*}\left(u_{i} ; z_{k}\right)-I\left(u_{i} ; z_{k}\right)\right] \\
& \mathrm{MSSE}=\frac{1}{N} \sum_{i=1}^{N} \frac{\left[I^{*}\left(u_{i} ; z_{k}\right)-I\left(u_{i} ; z_{k}\right)\right]^{2}}{\sigma\left(u_{i} ; z_{k}\right)^{2}}
\end{aligned}
$$

where $I^{*}\left(u_{i} ; z_{k}\right)$ and $I\left(u_{i} ; z_{k}\right)$ are the estimated and measured values at the $i$ th location, respectively, $N$ is the number of measured wells, and $\sigma\left(u_{i} ; z_{k}\right)^{2}$ is the kriging variance. The KME (kriging mean error) and MSSE (mean square standard error), which are close to zero and one, respectively, denote the best fitting models and parameters of variograms.

\section{Results and discussion}

This work used the gamv and ik $3 \mathrm{~d}$ codes in GSLIB (Deutsch and Journel, 1998) to compute the experimental variogram and indicator kriging. The estimates of As contamination were analyzed using the SPSS statistical package (SPSS Inc., 1998).

\subsection{Variogram analysis}

The As concentrations at the 50 (1st), 60 (2nd), 70 (3rd), 80 (5th) and 90 (6th)\% points on the percentage frequency distribution of As concentration measured in 2000, were used as the first five threshold values. The drinking water supply standard As concentration of $50 \mathrm{ppb}$ is used as the fourth threshold value, and corresponds to $72 \%$ of the percentage frequency distribution of the As concentration data measured in 2000 . The first five threshold values based on the measured As concentration frequency distribution were used to derive the conditional cumulative distribution function at each estimated grid point. This investigation is mainly concerned with the fourth threshold value, based on the drinking water supply standard.

Employing a least squares method to fit a variogram yields a model with the least fitting errors (Cressie, 1985). An omnidirectional variogram is first used to analyze the horizontally varying structures of As concentration. A lag increment of $3 \mathrm{~km}$ is used to obtain a stable variogram structure (Fig. 6). The spherical and exponential models give the best fits. Table 2 specifies the fitting parameters of these models. The fitted ranges, sills and nugget effects are $15 \sim 40 \mathrm{~km}, 0.08 \sim 0.25$ and $0.01 \sim 0.12$, respectively. The large-scale searching pairs in the horizontal direction are of Types I and II. The first pair in the horizontal variogram where $h$ is approximately $0.1 \sim 0.2 \mathrm{~km}$ yields a large variability. This pair represents a small-scale variability and should only be included to the variogram in vertical direction (Type III). The first pair is thus excluded from the horizontal large-scale variogram analysis. Lag increments of 0.025 and $0.03 \mathrm{~km}$ are used to 
establish a stable variogram in the vertical direction on a small scale (Fig. 6). The Gaussian and spherical models yield the best fitting. The nugget effects of the nested variogram are mainly inferred from the vertical variogram, which typically has the excellent spatial resolution. The fitted ranges and sills are $0.2 \sim 0.35 \mathrm{~km}$ and $0.12 \sim 0.21$, respectively.

To account for anisotropy along the horizontal direction, variograms are computed in various directions, separated by successive clockwise rotations of $15^{\circ}$ from north to south. The directional

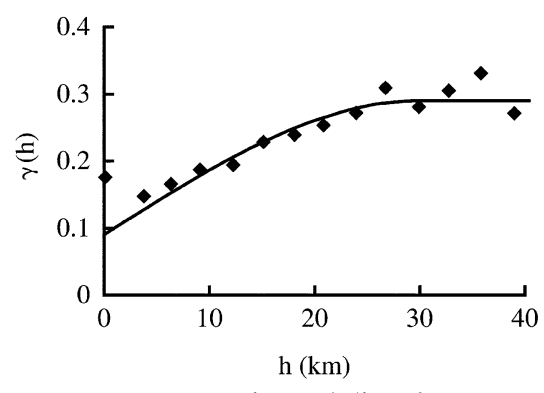

Horizontal direction

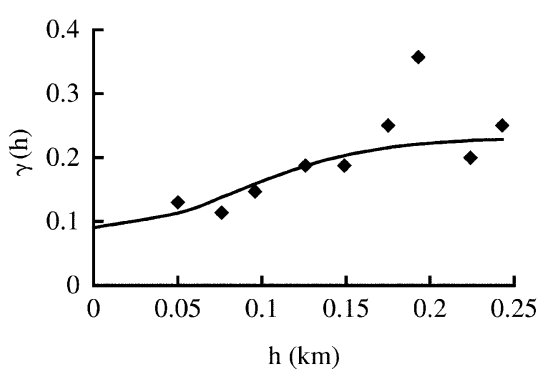

Vertical direction

(a) $1^{\text {st }}$ threshold $\left(\mathrm{z}_{\mathrm{k}}=16 \mu \mathrm{g} / \mathrm{l}\right)$

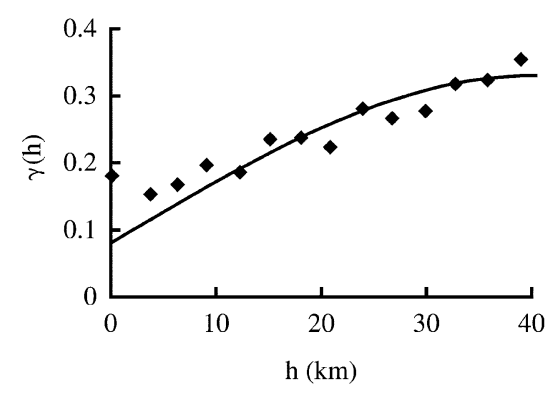

Horizontal direction

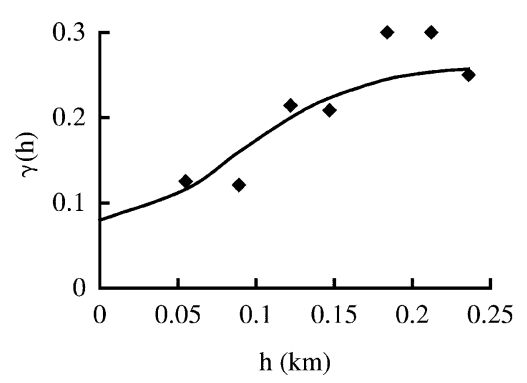

Vertical direction

(b) $2^{\text {nd }}$ threshold $\left(\mathrm{z}_{\mathrm{k}}=25 \mu \mathrm{g} / \mathrm{l}\right)$

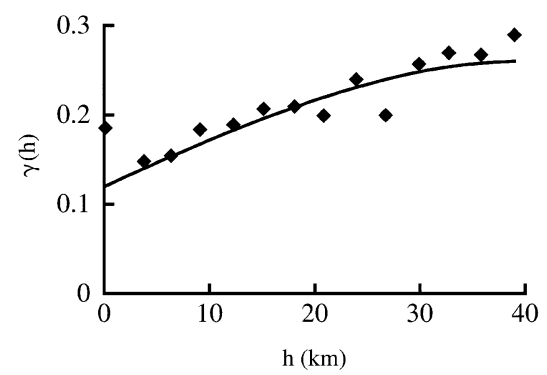

Horizontal direction

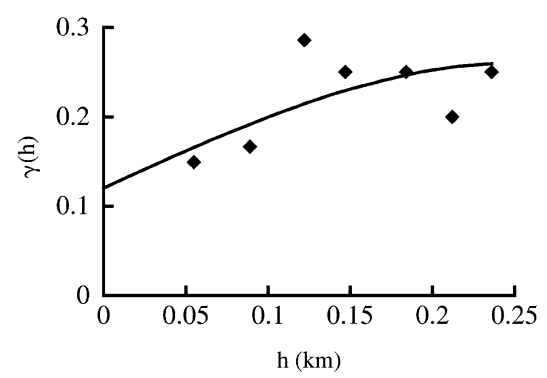

Vertical direction

(c) $3^{\text {rd }}$ threshold $\left(\mathrm{z}_{\mathrm{k}}=46 \mu g / l\right)$

Fig. 6. Experimental variograms indicator of As concentration and the fitting of theoretical models in horizontal and vertical directions for six thresholds. (Omni-directional variogram is applied to horizontal direction). 


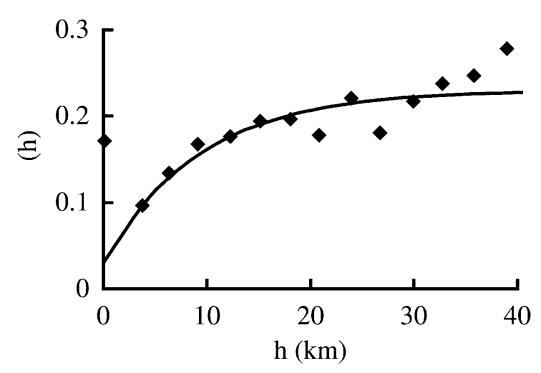

Horizontal direction

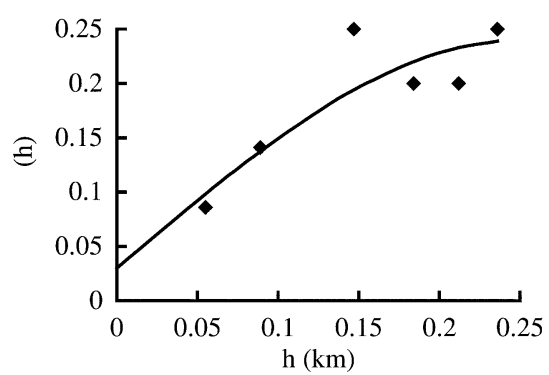

Vertical direction

(d) $4^{\text {th }}$ threshold $\left(\mathrm{z}_{\mathrm{k}}=50 \mu \mathrm{g} / \mathrm{l}\right)$

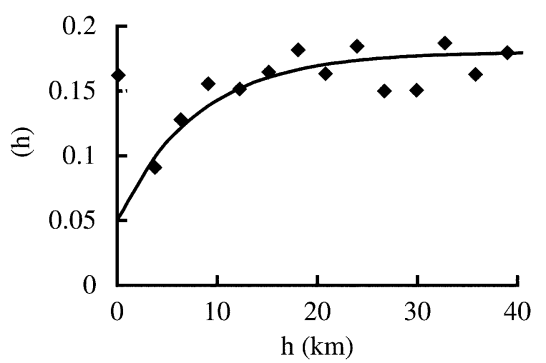

Horizontal direction

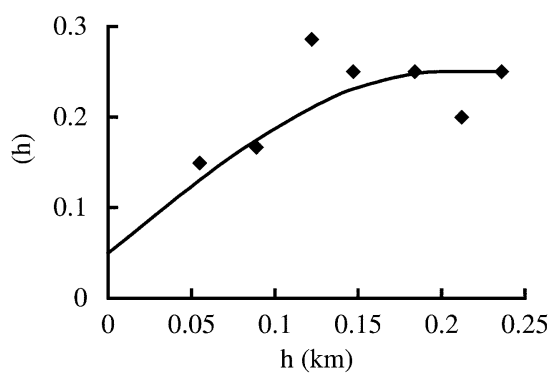

Vertical direction

(e) $5^{\text {th }}$ threshold $\left(\mathrm{z}_{\mathrm{k}}=94 \mu \mathrm{g} / \mathrm{l}\right)$

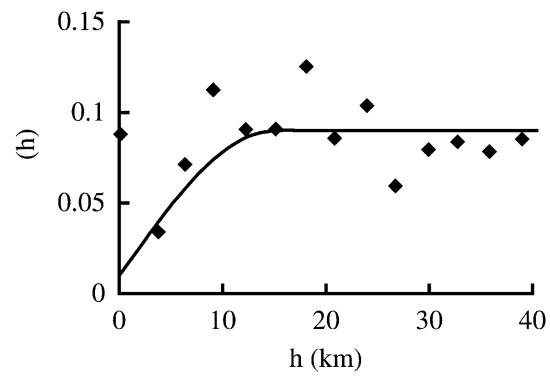

Horizontal direction

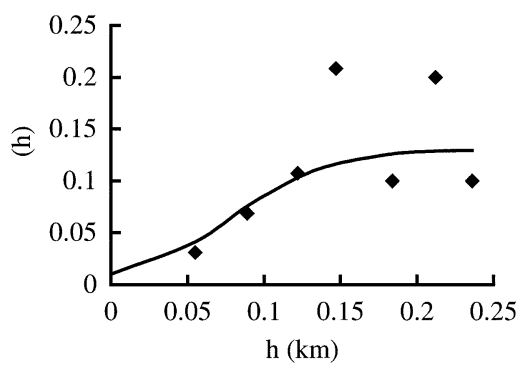

Vertical direction

(f) $6^{\text {th }}$ threshold $\left(\mathrm{z}_{\mathrm{k}}=163 \mu \mathrm{g} / \mathrm{l}\right)$

Fig. 6 (Continued).

experimental variogram searches for pairs with an angular tolerance of $30^{\circ}$. However, experimental variograms inevitably oscillate at a specific correlation distance because insufficient data pairs and non-uniformly distributed wells are involved.

The models that were fit to omnidirectional variograms were also used to model the anisotropic variability. The determined directions of maximum variability for each threshold range from $\mathrm{N}$ to $\mathrm{N} 30^{\circ} \mathrm{E}$, and is $\mathrm{N}$ for four thresholds. The anisotropic ratio (maximum range/minimum range) is approximately $1.88 \sim 3.18$ (Table 2).

Table 2 also lists cross-validation results to examine the validity of the fitting models and 
Table 2

Fitted parameters of the theoretical variogram model for six thresholds of As indicator variable

\begin{tabular}{|c|c|c|c|c|c|c|c|c|c|c|c|}
\hline Threshold & Direction & Model type & $\begin{array}{l}\text { Nugget } \\
\text { effect }\end{array}$ & Sill & $\begin{array}{l}\text { Range } \\
(\mathrm{km})\end{array}$ & $\begin{array}{l}\text { Max. } \\
\text { range } \\
(\mathrm{km})\end{array}$ & $\begin{array}{l}\text { Min. } \\
\text { range } \\
(\mathrm{km})\end{array}$ & $\begin{array}{l}\text { Anisotropic } \\
\text { ratio }\end{array}$ & $\begin{array}{l}\text { Max. } \\
\text { variability } \\
\text { direction }\end{array}$ & KME & MSSE \\
\hline \multirow[t]{2}{*}{$1 \mathrm{st}$} & $\mathrm{H}^{*}$ & Spherical & 0.09 & 0.2 & 30 & 40 & 20 & 2 & $\mathrm{~N}$ & -0.009 & 1.18 \\
\hline & $\mathrm{V}^{* *}$ & Gaussian & 0.09 & 0.14 & 0.35 & - & - & - & - & & \\
\hline \multirow[t]{2}{*}{$2 \mathrm{nd}$} & $\mathrm{H}$ & Spherical & 0.08 & 0.25 & 40 & 45 & 24 & 1.88 & $\mathrm{~N} 30^{\circ} \mathrm{E}$ & 0.008 & 0.99 \\
\hline & $\mathrm{V}$ & Gaussian & 0.08 & 0.18 & 0.35 & - & - & - & - & & \\
\hline \multirow[t]{2}{*}{$3 r d$} & $\mathrm{H}$ & Spherical & 0.12 & 0.14 & 40 & 45 & 18 & 2.5 & $\mathrm{~N} 15^{\circ} \mathrm{E}$ & 0.009 & 0.91 \\
\hline & $\mathrm{V}$ & Spherical & 0.12 & 0.14 & 0.25 & - & - & - & - & & \\
\hline \multirow[t]{2}{*}{4 th } & $\mathrm{H}$ & Exponential & 0.03 & 0.2 & 28 & 35 & 15 & 2.33 & $\mathrm{~N}$ & 0.009 & 0.79 \\
\hline & V & Spherical & 0.03 & 0.21 & 0.25 & - & - & - & - & & \\
\hline \multirow[t]{2}{*}{5 th } & $\mathrm{H}$ & Exponential & 0.05 & 0.13 & 24 & 35 & 11 & 3.18 & $\mathrm{~N}$ & 0.006 & 0.75 \\
\hline & V & Spherical & 0.05 & 0.2 & 0.2 & - & - & - & - & & \\
\hline \multirow[t]{2}{*}{ 6th } & $\mathrm{H}$ & Spherical & 0.01 & 0.08 & 15 & 22 & 10 & 2.2 & $\mathrm{~N}$ & 0.004 & 1.05 \\
\hline & V & Gaussian & 0.01 & 0.12 & 0.3 & - & - & - & - & & \\
\hline
\end{tabular}

*H: horizontal, **V: vertical

parameters of variograms. The KMEs range from -0.009 to 0.009 and the MSSEs range from 0.75 to 1.18 . The KMEs are close to zero. In a crossvalidation procedure, Chilès and Delfiner (1999) proposed the MSSE with a tolerance interval of $1 \pm 3 \sqrt{2 / N}$ (i.e. $[0.59,1.41]$ ). The MSSEs of this study fall within the proposed tolerance range.

\subsection{Indicator kriging estimation}

Indicator kriging was used to estimate the probability of As contamination, based on 3D anistropic variogram models. Each aquifer was horizontally discretized into a grid of $27 \times 19$ cells, with a $2 \mathrm{~km}$ spacing. The elevation of the aquifers varied irregularly, so the grid used in the estimation was set by the midpoints of each aquifer in the vertical direction.

The probability of contamination $(P(u ; 50))$ is mapped for the three aquifers in Fig. 7. The southwestern coastal aquifer has a high probability of contamination by As, whereas the banks of the Chou-Shui River have a low probability, especially in the proximal-fan area. The highest measured As concentration $(640 \mu \mathrm{g} / 1)$ was in aquifer 1 of the Ming-Der monitoring well in the western Yun-Lin. However, the highest As contamination probability determined using indicator kriging appears in the south of the Ming-Der monitoring well. Indicator kriging compares the set threshold value with the measured As concentration and then transforms the measured concentration to 0 or 1 . The largest threshold value used in this study is $163 \mu \mathrm{g} / \mathrm{l}$, corresponding to $90 \%$ of the cumulative frequency distribution of the measured As concentrations. If the measured As concentrations exceed the 163 $\mu \mathrm{g} / 1$ threshold, then the indicator variables are all set to zero and cannot reflect the extremely high measured As concentration, such as of $640 \mu \mathrm{g} / \mathrm{l}$. Notably, Goovaerts (1997) stated that measured data above $90 \%$ of the cumulative frequency distribution cannot be suitably set as thresholds for indicator kriging. Moreover, the kriging method applies the weighted moving-average technique to estimate the unknown concentrations at the neighboring points. If the estimated concentrations all exceed the threshold set in adjacent regions, then indicator kriging assigns a high probability of contamination in the region of interest. The As concentration in the points that neighbor the MingDer monitoring well is relatively low, reducing the probability of contamination in the vicinity. Furthermore, because the 3D anisotropic model was used to estimate the neighboring As concentrations in the deep aquifer, the weighted moving-average technique uses the high As concentrations in the upper aquifers to calculate contamination probability in aquifer 3 . Indicator kriging estimates a $0.2 \sim 0.6$ probability of As contamination in the southwestern area of aquifer 3 , only one or two 


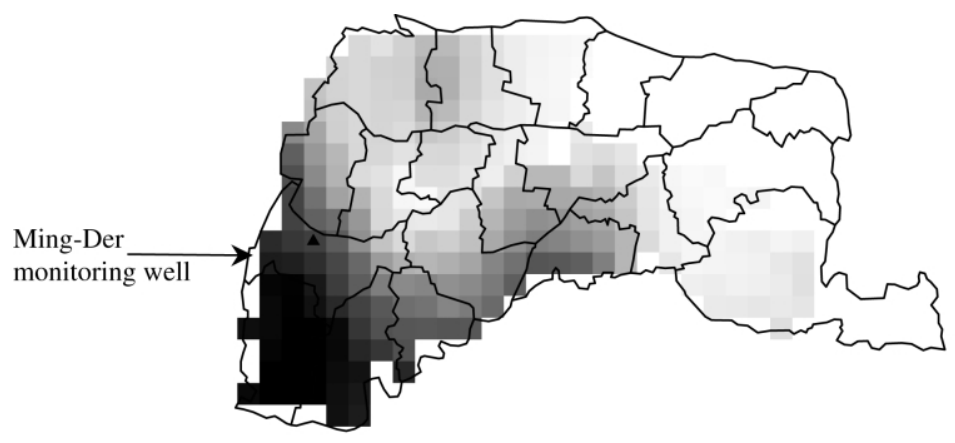

(a) Aquifer 1

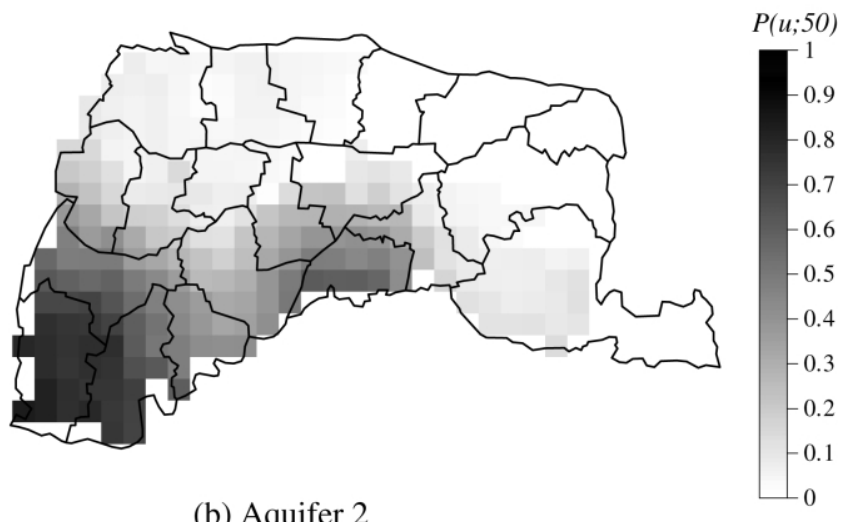

(b) Aquifer 2

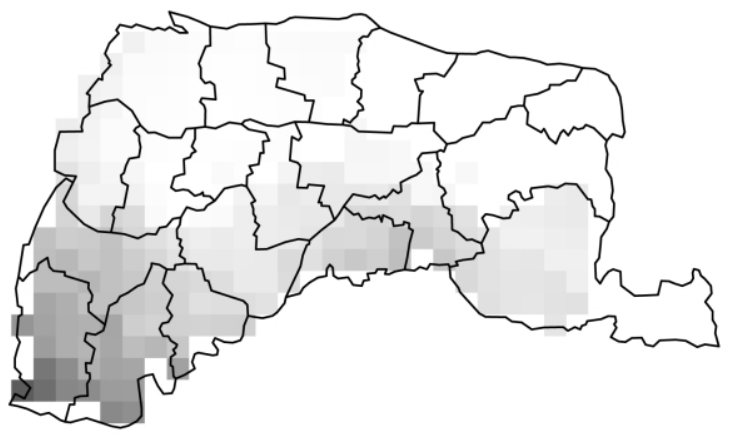

(c) Aquifer 3

Fig. 7. Estimated probability distribution of the As concentration that exceeds the standard of drinking water supply in the Yun-Lin county, Taiwan using indicator kriging.

As concentrations in the monitoring wells exceed the standard for the drinking water supply.

The statistical analysis of the estimated probabilities of As contamination of 513 cells in the three aquifers indicates that the average and maximum contamination probability of contamination of aquifers 1,2 and 3 are 0.34 and $0.97 ; 0.28$ and 0.84 , and 0.15 and 0.67 , respectively (Table 3 ). 
Table 3

Statistics of estimated probability of As concentrations exceeding the standard of drinking water supply by indicator kriging

\begin{tabular}{llll}
\hline Statistic & \multicolumn{2}{l}{ Aquifer } \\
\cline { 2 - 4 } & 1 & 2 & 3 \\
\hline Mean & 0.34 & 0.28 & 0.15 \\
Median & 0.23 & 0.22 & 0.12 \\
Standard deviation & 0.30 & 0.25 & 0.14 \\
Skewness & 0.54 & 0.56 & 1.00 \\
Minimum & 0.00 & 0.00 & 0.00 \\
Maximum & 0.97 & 0.84 & 0.67 \\
\hline
\end{tabular}

The shallow aquifers 1 and 2 have a higher probability of As contamination than the deep aquifer 3 .

\subsection{As contamination potential of twenty townships}

The Arcview 3.2 (ESRI, 1998) GIS map of 20 townships in the Yun-Lin was overlaid on the As probability maps, to determine the average probability of As contamination potential in each township. The As contamination potential was specified using five levels. The first level denotes an As contamination probability of less than 0.2 corresponding to unpolluted groundwater. If the As contamination probability exceeds 0.2 , then the groundwater is considered polluted and is not suitable for supply as drinking water. The ranges of probabilities of As contamination in the second, third, fourth and fifth levels are $0.2 \sim 0.4,0.4 \sim 0.6$, $0.6 \sim 0.8$, and $0.8 \sim 1.0$, respectively. A high level of the contamination potential corresponds to a high As contamination probability and a high risk to human health.

Table 4 shows the As contamination potential of 20 townships from high to low, and Fig. 8 depicts the spatial distribution of As contamination potential. The contamination potential in aquifer 1 in Kou-Hu reaches the highest fifth level and the corresponding As contamination probability is 0.92. Drinking groundwater from aquifer 1 in Kou$\mathrm{Hu}$ is an immediate and high risk to human health. In four places, including aquifer 2 in $\mathrm{Kou}-\mathrm{Hu}$, aquifers 1 and 2 in Shuei-Lin, and aquifer 1 in
Sih-Hu, the As contamination potential reaches the fourth level. In five places, including aquifer 2 in Sih-Hu, aquifers 1 and 3 in Da-Bi, aquifers 1 and 2 in Pei-Kang, the As contamination potential reaches the third level. In 11 places, it reaches the second level and in all the remaining places, it reaches the first level. Notably, the As contamination potential of all three aquifers in Si-Luo, Cih-Tong and Lin-Nei are zero, representing no As contamination.

The high contamination potential of As is confined to the southwest coastal area and along the Pei-Kang River banks. The township of Kou-Hu, with the highest As contamination potential, is located in the junction between the southwest coastal area and the Pei-Kang River bank. Results indicate that the probability of contamination of aquifer 1 exceeds that of aquifer 2 , and that aquifer 3 is the least likely to be contaminated, among the three aquifers. There are only four southwestern townships of the Yun-Lin where their aquifer 3 reach the second level of As contamination potential.

Table 4

Estimated As contamination potential order of 20 townships in the Yun-Lin county, Taiwan

\begin{tabular}{lllll}
\hline Township & Aquifer 1 & Aquifer 2 & Aquifer 3 & $\sum$ \\
\hline 1. Mai-Liao & 0.18 & 0.05 & 0.01 & 0.24 \\
2. Er-Lun & 0.04 & 0.02 & 0.01 & 0.07 \\
3. Lun-Bei & 0.16 & 0.04 & 0.01 & 0.21 \\
4. Si-Luo & 0.00 & 0.00 & 0.00 & 0.00 \\
5. Cih-Tong & 0.00 & 0.00 & 0.00 & 0.00 \\
6. Lin-Nei & 0.00 & 0.00 & 0.00 & 0.00 \\
7. Tai-Si & 0.37 & 0.21 & 0.07 & 0.65 \\
8. Dou-Liou & 0.02 & 0.02 & 0.02 & 0.06 \\
9. Tu-Ku & 0.28 & 0.25 & 0.06 & 0.59 \\
10. Hu-Wei & 0.19 & 0.16 & 0.05 & 0.40 \\
11. Bao-Jhong & 0.10 & 0.06 & 0.01 & 0.17 \\
12. Dong-Shih & 0.18 & 0.19 & 0.05 & 0.42 \\
13. Dou-Nan & 0.15 & 0.21 & 0.14 & 0.50 \\
14. Sih-Hu & 0.65 & 0.53 & 0.21 & 1.39 \\
15. Gu-Keng & 0.07 & 0.08 & 0.10 & 0.25 \\
16. Yuan-Chang & 0.35 & 0.31 & 0.09 & 0.75 \\
17. Da-Bi & 0.50 & 0.52 & 0.17 & 1.19 \\
18. Kou-Hu & 0.92 & 0.75 & 0.36 & 2.03 \\
19. Shuei-Lin & 0.77 & 0.64 & 0.30 & 1.71 \\
20. Pei-Kang & 0.55 & 0.42 & 0.21 & 1.18 \\
\hline
\end{tabular}




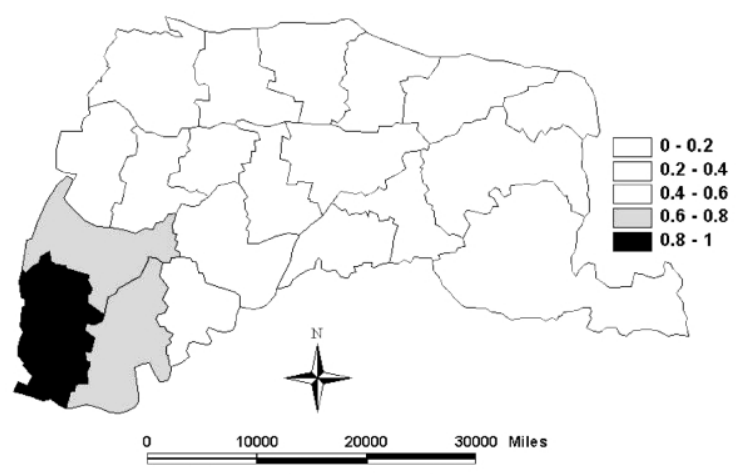

(a) Aquifer 1

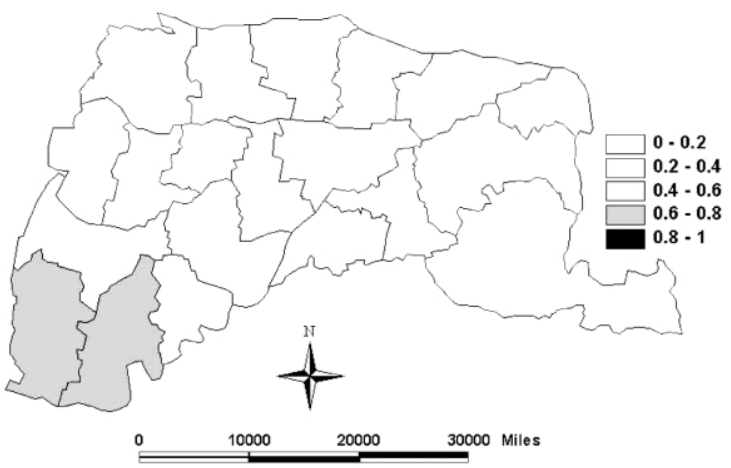

(b) Aquifer 2

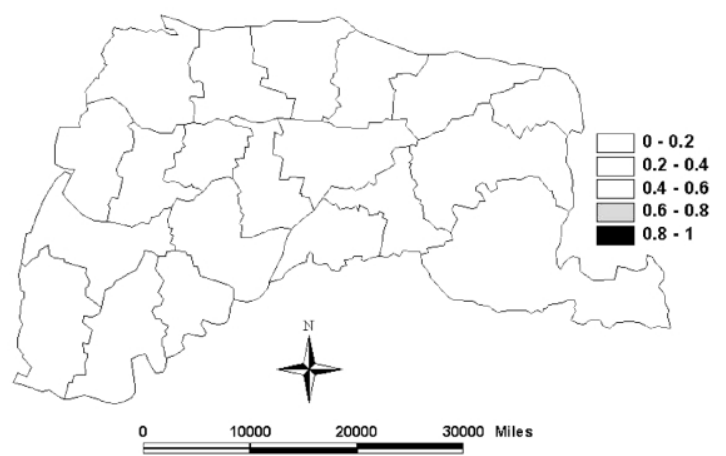

(c) Aquifer 3

Fig. 8. Estimated contamination potential of As concentration exceeding the standard of drinking water supply in 20 townships of the Yun-Lin county, Taiwan.

\section{Conclusions}

High As contamination is detected throughout the coastal aquifer of the Yun-Lin, Taiwan. Groundwater quality data, obtained from multi- level monitoring wells, indicated that the As concentration far exceeds the drinking water supply standard and poses a serious threat to public health. This work adopted indicator kriging to estimate the probabilistic risk of As pollution in the YunLin area. A 3D variogram model analyzed the As concentration probability, using an indicator variable with multi-level thresholds. The method solved the problem of data scarcity, increased the number of searching pairs for calculating an experimental variogram in the vertical direction, and provided multi-level thresholds in the probability estimation of contamination.

The estimates reveal that the high As pollution probability is distributed in the southwest coastal area and along the Pei-Kang River bank. Among 20 townships of the Yun-Lin county, Kou-Hu has the highest As contamination potential in its shallow aquifer. Shallow aquifers 1 and 2 (depth $<$ $180 \mathrm{~m}$ ) have high As contamination potentials and cannot be used to supply drinking water. The deep aquifer 3 (depth $>190 \mathrm{~m}$ ) has a low As contamination potential and may be used for supplying drinking water, except in Kou-Hu, Sih-Hu, ShueiLin and Pei-Kang where the As contamination potentials are at the second level and still represent a risk to human health.

\section{Acknowledgments}

The authors would like to thank the National Science Council of the Republic of China for financially supporting this research Under Contract Nos. NSC 90-2313-B-002-322 and NSC 91-2313B-002-270.

\section{References}

Boman GK, Molz FJ, Güven O. An evaluation of interpolation methodologies for generating three-dimensional hydraulic property distributions from measured data. Ground Water 1995;33(2):247-258.

Castrignanò A, Goovaerts P, Lulli L, Bragato G. A geostatistical approach to estimate probability of occurrence of Tuber melanosporum in relation to some soil properties. Geoderma 2000;98:95-113.

Central Geological Survey. Project of groundwater monitoring network in Taiwan during first stage-research report of 
Chou-Shui River alluvial fan. Taiwan: Water Resources Bureau, 1999. p. 383

Chen CJ, Wang CJ. Ecological correlation between arsenic level in well water and aged-adjusted mortality from malignant neoplasms. Cancer Res 1990;50:5470-5474.

Chen CJ, Hsueh YM, Lai MS, Shyu MP, Chen SY, Wu MM, Kuo TL, Tai TY. Increased prevalence of hypertension and long-term arsenic exposure. Hypertension 1995;25:53-60.

Chilès JP, Delfiner P. Geostatistics: modeling spatial uncertainty. New York: John Wiley and Sons Inc, 1999. p. 283-287.

Chiou HY. Epidemiologic studies on inorganic arsenic methylation capacity and inorganic arsenic induced health effects among residents in the blackfoot disease endemic area and Lanyang basin in Taiwan. Doctoral Dissertation, Institute of Epidemiology, College of Public Health, National Taiwan University, Taiwan, 1996: p. 8.

Cressie N. Fitting variogram models by weighted least square. Math Geol 1985;17:563-586.

Cressie N. Statistics for spatial data. New York: Wiley, 1993.

Deutsch CV, Journel AG. GSLIB: Geostatistical software library and user's guide. 2nd ed. New York, USA: Oxford University Press, 1998.

Eggleston JR, Rojstaczer SA, Peirce JJ. Identification of hydraulic conductivity structure in sand and gravel aquifers, Cape Cod data set. Water Resour Res 1996;32:1209-1222.

ESRI. Arcview. Redlands, CA: ESRI (Environmental Systems Research Institute), 1998.

Fogg GE, LaBolle EM, Weissman GS. Groundwater vulnerability assessment: hydrologic perspective and example from Salinas Valley, California. Assessment of non-point source pollution in the Vadose zoneAmerican Geophysical Union, 1999. p. 45-61 (Geophysical Monograph 108).

Geng CC, Hsueh CH, Kung CS. Modeling of the groundwater flow and land subsidence in Yun-Chia plain and Yun-Lin offshore industrial area. Conference on Groundwater Research and Quality Protection, Taiwan, 1994: 453-472.

Goovaerts P. Geostatistics for natural resources evaluation. New York: Oxford University Press, 1997. p. 259-368.

Hess KM, Wolf SH, Celia MA. Large-scale natural gradient tracer test in sand and gravel, Cape Cod, Massachusetts 3. Hydraulic conductivity variability and calculated macrodispersivites. Water Resour Res 1992;28:2011-2027.

Isaaks EH, Srivastava RM. An introduction to applied geostatistics. New York: Oxford University Press, 1989. p. $278-$ 322.

Istok JD, Pautman CA. Probabilistic assessment of groundwater contamination 2. Results of case study. Ground Water 1996;34(6):1051-1064.

Journel AG, Huijbregts CJ. Mining geostatistics. San Diego: Academic Press, 1978.

Juang KW, Lee DY. Simple indicator kriging for estimating the probability of incorrectly delineating hazardous areas in a contaminated site. Environ Sci Technol 1998;32:24872493.

Lai MS, Hsueh YM, Chen CJ, Shyu MP, Chen SY, Kuo TL, Wu MM, Tai TY. Ingested inorganic arsenic and prevalence of diabetes mellitus. Am J Epidemiol 1994;139:484-492.
Li GC, Fei WC, Yen PY. Survey of arsenical residual level in the rice paddy soil and water samples from different locations of Taiwan. Natl Sci Council Mon, ROC 1979;7(8):798-809.

Lin YP, Chang TK, Shih CW, Tseng CH. Factorial and indicator kriging methods using a geographic information system to delineate spatial variation and pollution sources of soil heavy metals. Environ Geol 2002;42:900-909.

Liu CW, Jang CS, Chen SC. Three-dimensional spatial variability of hydraulic conductivity in the Choushui River alluvial fan, Taiwan. Environ Geol 2002;43(1-2):48-56.

McCord JT, Gotway CA, Conrad SH. Impact of geologic heterogeneity on recharge estimation using environmental tracers: numerical modeling investigation. Water Resour Res 1997;33(6):1229-1240.

Nakaya S, Yohmei T, Koike A, Hirayama T, Yoden T, Nishigaki M. Determination of anisotropy of spatial correlation structure in a three-dimensional permeability field accompoied by shallow faults. Water Resour Res 2002;38(8):10.1029/2001WR000672.

NRC (National Research Council). Ground water vulnerability assessment: predictive relative contamination potential under conditions of uncertainty. Washington, DC: National Academy Press, 1993. p. 42-63.

Oyedele DJ, Amusan AA, Obi A. The use of multiple-variable indicator kriging technique for assessment of the suitability of an acid soil for maize. Trop Agric 1996;73(4):259-263.

Rehfeldt KR, Boggs JM, Gelhar LW. Field study of dispersion in a heterogeneous aquifer 3. Geostatistical analysis of hydraulic conductivity. Water Resour Res 1992;28:33093324.

Shen SB. Study on land subsidence in coastal plains in YunLin area (I). Conference on Land Subsidence, Taiwan, 1989, pp. 191-211.

Shen YS, Chin CS. Relation between blackfoot disease and pollution of drinking water by arsenic in Taiwan. NY: Pergamon Press, 1964. p. 175-182 (Adv Water Pollut Res).

Smith JL, Halvorson JJ, Papendick RI. Using multiple-variable indicator kriging for evaluating soil quality. Soil Sci Soc Am J 1993;57:743-749.

SPSS Inc.. SPSS BASE 8.0-Application Guide. Chicago: SPSS Inc, 1998.

Taiwan Sugar Company. Establishment and operational management of groundwater monitoring network. Taiwan: Water Resources Bureau, 1997. p. 2-12.

Taiwan Sugar Company. Water quality survey and analysis of groundwater monitoring network. Taiwan: Water Resources Bureau, 2001. p. 68-74.

Tsao YS, Wang JL. A comprehensive study of sea water intrusion for the Yun-Lin aquifer system. Taiwan: Agricultural Engineering Research Center, 1984. p. 159

Tseng WP. Effects and dose-response relationships of skin cancer and blackfoot disease with arsenic. Environ Health Perspect 1977;19:109-119. 
van Meirvenne M, Goovaerts P. Evaluating the probability of exceeding a site-specific soil cadmium contamination threshold. Geoderma 2001;102:75-100.

Wu MM, Kuo TL, Hwang YH, Chen CJ. Dose-response relation between arsenic well water and mortality from cancers and vascular diseases. Am J Epidemiol 1989;130:1123-1132.

Yen FS, Long CN, Lu TH. An environmental model of high arsenic concentration in the groundwater aquifer of Taiwan. J Taiwan Environ Sanitation 1980;12(1):66-80. 